\title{
DISTINTIVIDAD Y USO DE LAS MARCAS COMERCIALES
}

\author{
DISTIN CTIVENESS AND USE OF TRADEMARKS
}

\section{ChRistian SCHMitz VACCARO*}

\begin{abstract}
RESU MEN: En la economía globalizada actual resulta fundamental diferenciar los productos propios de los de la competencia. Para ello es esencial contar con una marca que posea capacidad distintiva, puesto que es esta la que permite al consumidor identificar el origen empresarial del producto o servicio.

La distintividad constituye una característica, función y requisito de registro de las marcas comerciales. Se trata de un concepto flexible y dinámico en el tiempo, que varía de acuerdo al uso que se le dé al signo marcario. Así, la forma de cómo se usa el signo condiciona su distintividad, sea para obtenerla, aumentarla o incluso para perderla, lo cual a su vez puede incidir en el registro marcario. Ello constituye el fundamento de la estrecha vinculación entre uso de la marca, su capacidad distintiva y el registro marcario.
\end{abstract}

Palabras dave propiedad intelectual, marca comercial, distintividad, uso adecuado de la marca.

ABSTRACT: In today's global economy is essential to differentiate the own products from competitors ones. It is therefore fundamental to have a brand that has distinctive capacity, since it is this that enables consumers to identify the commercial origin of the product or service.

Distinctiveness is a feature, function and requirement for registration of trademarks. It is a flexible and dynamic concept, which varies according to the use of the trademark sign. In that sense, the way of how to use the sign determines its distinctiveness, creating, increasing or even loosing the trademark, which could affect the registration of trademark. This is the basis of the close link between use of the mark, its distinctive capacity and trademark registration.

Key words intellectual property, trademark, distinctiveness, proper trademark usage.

\section{INTRODUCCIÓN}

La globalización ha dado origen a mercados globales habitados por consumidores globales, que demandan verdaderos productos y servicios globales, los cuales son comercializados, distribuidos, licenciados, prestados y/o transferidos hasta los más remotos rincones del globo. $\mathrm{N}$ aturalmente ello trae aparejado niveles de competitividad nunca antes vistos, de manera que algunos hablan de una hipercompetitividad. En efecto, la compe-

\footnotetext{
* Abogado, Licenciado en Ciencias Jurídicas,U niversidad de Concepción. M agíster en Administración de Empresas (MBA-UC), Pontificia Universidad Católica de Chile y Magíster (c) en Derecho Privado,Universidad Nacional de Rosario, Argentina. Profesor Adjunto de Derecho Económico y Derecho Informático Universidad Católica de la Santísima C oncepción, D ocente de D erecho Económico, Universidad San Sebastián, Concepción. Email: schmitz@ucsc.cl
} 
tencia hoy ya no solo se produce entre empresas locales, sino que estas compiten con empresas provenientes de otros países y de otros continentes, produciéndose así también una competencia que es global.

Frente a ese alto grado de competitividad que rige el mundo empresarial, las compañías han tenido que aprender a diferenciarse a sí mismas, pero en especial a sus bienes y servicios de los de la competencia. Si en el pasado ya era importante diferenciarse, en un entorno hipercompetitivo aún es más importante la función diferenciadora que busca el marketing. En ese sentido, son precisamente las marcas las que constituyen una herramienta fundamental para distinguirse y orientar al consumidor o cliente a identificar lo que él necesita y busca.

La temática de las marcas comerciales involucra aspectos económico-comerciales y jurídicos. Pese a ello, tradicionalmente el estudio de dichos aspectos se ha llevado a cabo enteramente separado; así los economistas e ingenieros comerciales se abocan al primero, mientras que los abogados al segundo.

En el presente trabajo nos proponemos analizar el tema, con un enfoque amplio. Por lo tanto, no pretendemos extraer y aislar únicamente los aspectos jurídicos involucrados, sino estudiar el tema de la distintividad y el uso de las marcas comerciales de una forma más integral, lo cual implica respetar la existencia de factores multidisciplinarios que se entrelazan y se explican recíprocamente. D e otra forma, tampoco sería posible entender cabalmente las razones y trasfondos que motivan esta institución y la construcción de una estrategia conjunta entre abogados y administradores de empresas, que resulta indispensable a la hora de crear, usar y defender una marca comercial.

\subsection{Concepto y funciones de la Marca}

En forma simple podemos decir que una marca es un signo que permite diferenciar los bienes o servicios de una empresa frente a los de las demás empresas que operan en el mercado. En general las definiciones, tanto de economistas como juristas, recogen los elementos de diferenciación y competencia.

Así por ejemplo, Stanton, Etzel y Walker señalan que "una marca es un nombre y/0 señal cuya finalidad esidentificar el producto de un vendedor o grupo de vendedores, para diferenciarlo de los productos rivales" 1.

El jurista Eli Salis define "marca como todo signo o medio que sirve para distinguir en el mercado los productos o servicios de una persona física o jurídica de los de otra" 2.

Pero también las definiciones legales siguen el mismo criterio. Así, en Europa, el antiguo Reglamento (CE) N ${ }^{\circ}$ 40/94 del Consejo de 20 de diciembre de 1993 sobre la marca comunitaria define a estas como "todos los signos que puedan ser objeto de una representación gráfica, en particular las palabras, incluidos los nombres de personas, los dibujos, las letras, las cifras, la forma del producto o de su presentación, con la condición de que tales signos sean apropiados para distinguir los productos o los servicios de una empresa de los de otras empresas".

\footnotetext{
${ }^{1}$ Stanton et al. (2000) p. 264.

2 Salis (2006) p. 122.
} 
Por su parte, en los EE.UU ., el $\S 1127$ del Código (15 U S.C.) señala que el término marca comercial ["trademark"] incluye "any word, name, symbol, or device, or any combination thereof

(1) used by a person, or

(2) which a person has a bona fide intention to use in commerce and applies to regi ster on the principal register established by this chapter, to identify and distinguish his or her goods, including a unique product, from those manufactured or sold by others and to indicate the source of the goods, even if that source is unknown"3.

En nuestro país, la Ley 19.039 de Propiedad Industrial, en su artículo 19, entrega la siguiente definición: "Bajo la denominación de marca comercial, se comprende todo signo que sea susceptible de representación gráfica capaz de distinguir en el mercado productos, servicios o establecimientos industriales o comerciales".

En cuanto a su naturaleza jurídica, las marcas comerciales son un derecho de propiedad industrial, y como tal comparten las características propias de este subsistema de la propiedad intelectual: intangibilidad, exclusividad, territorialidad y en cierta medida temporalidad.

Vale la pena destacar que algunos doctrinarios realizan clasificaciones de la propiedad industrial, y en tal caso resulta útil ubicar las marcas comerciales dentro de la respectiva clase. Una división muy utilizada es la que sigue la O rganización M undial de Comercio, que en materia de propiedad industrial, distingue entre protección de innovaciones, invenciones y creaciones tecnológicas, y protección de signos distintivos, tales como las marcas de comercio, marcas de fábrica e indicaciones geográficas ${ }^{4}$. Los signos distintivos tienden al resguardo de la competencia desleal y de consumidores, contribuyendo a una decisión informada de compra de bienes y servicios.

Concordamos con la necesidad de clasificar los distintos derechos que conforman la propiedad industrial, debido a su naturaleza jurídica tan disímil. Ello resulta evidente cuando se toma en cuenta que las funciones que cumplen los diversos derechos industriales son claramente distintas.

La doctrina se encuentra uniforme en cuanto a que la función fundamental de las marcas radica en su distintividad, y las demás funciones simplemente se derivan de tal capacidad o se someten a esta 5 . Así, para 0 tamendi "la verdadera y única función esencial de la marca es distinguir un producto 0 un servicios de otros" ${ }^{6}$. Volveremos más adelante sobre el punto.

Sin perjuicio de lo anterior, Cabanellas de las Cuevas reconoce la existencia de otras funciones secundarias de las marcas:

\footnotetext{
3 U.S. Code, Title 15-Commerce and Trade, Chapter 22-Trademarks, Subchapter III-General Provisions, $\S 1127$.

${ }^{4}$ Organización Mundial de Comercio: "¿Q ué se entiende por derechos de propiedad intelectual?"

${ }^{5}$ En ese sentido, opinan tanto $O$ tamendi como $C$ abanellas de las $C$ uevas, cada uno de los cuales por separado ha publicado una obra titulada "D erecho de M arcas", y sin perjuicio de la abundante doctrina referida por estos autores.

${ }^{6}$ OtAMENdi (2010) p. 3.
} 
1. función de identificación del origen de los bienes y servicios

2. función de garantía de calidad

3. función publicitaria e informativa

4. función competitiva

5. función de protección del titular de la marca

6. función de protección del consumidor

7. función y efectos económicos de las marcas en los países subdesarrollados?

Por nuestra parte, nos centraremos en el presente trabajo en la función distintiva de las marcas, tema en el cual ahondaremos a continuación.

\section{DISTINTIVIDAD Y DIFERENCIACIÓN, DOS CONCEPTOS RELACIONADOS}

Como anticipado al definir la marca, la distintividad es el elemento esencial y la razón de ser de las marcas comerciales. Al mismo tiempo aparece otro término que se vincula estrechamente con las marcas que es el de la diferenciación. No podemos soslayar las similitudes funcionales y estrecha vinculación que en los hechos se presenta entre ambos conceptos; lo cual queda demostrado cuando algunos precisan que "la diferenciación de productos ocurre cuando a los ojos del público una compañía distingue su producto de las marcas que la competencia ofrece al mismo mercado agregado" 8.

Sin embargo, para evitar confusiones y también para entender cabalmente la función y la operatividad práctica de las marcas, creemos importante analizar más a fondo estos dos conceptos - distintividad y diferenciación- para lo cual recurrimos a su sentido natural y obvio. Distintividad proviene del verbo "distinguir", mientras que diferenciación del verbo "diferenciar". El significado de dichos verbos es el siguiente9:

- "D istinguir": "1. C onocer la diferencia que hay de unas cosas a otras.

2. H acer que algo se diferencie de otra cosa por medio de alguna particularidad, señal, divisa, etc."

- "D iferenciar": "1. H acer distinción, conocer la diversidad de las cosas.

2. H acer a alguien 0 algo diferente, diverso de otro".

Si nos centramos respectivamente en la segunda acepción, advertimos que al aplicarlas al objeto del presente estudio, se llega al siguiente resultado:

- "distinguir" implica hacer que un producto (bien o servicio) se diferencie de otros productos por medio de una marca, y

\footnotetext{
${ }^{7}$ Bertone y Cabanellas de las Cuevas (2008 I) p. 35 a 70.

${ }^{8}$ Stanton et al. (2000) p. 189.

${ }^{9}$ Según el D iccionario de la Lengua Española de la Real Academia Española, 22ª edición.
} 
- "diferenciar" significaría hacer a un producto (bien o servicio) diferente, diverso de otro.

De este modo, la distintividad se asocia más al medio, esto es la marca, mientras que la diferenciación se enfocaría en el objeto mismo, el producto. Con ello llegamos a aseverar que la distintividad posee una connotación jurídica, mientras que la diferenciación se relaciona con el ámbito del marketing y la publicidad. Sin perjuicio de reconocer la interrelación existente entre ambos conceptos, confirmamos lo anterior al observar que en la práctica la secuencia lógica se inicia por un requerimiento económico de diferenciación, planteada por algún administrador, empresario o encargado de marketing. Ahí surge la marca como instrumento para lograr tal diferenciación. Luego la protección jurídica de la marca se encarga a un abogado, quien pondrá énfasis en la exigencia de la distintividad para obtener el registro de la marca. En consecuencia, observamos que la necesidad de diferenciación que surge al introducir un producto al mercado, se soluciona principalmente mediante el uso de un signo marcario, y este logra exclusividad cuando es registrado, para lo cual se exige distintividad.

Cuando establecemos la relación antes dicha, en el sentido de hablar de diferenciación de productos y distintividad de marcas, nos encontramos con el problema típico de la confusión entre producto y marca, sobre el cual mucho se ha escrito. En este lugar solo deseamos resumir esta cuestión a través de la cita de tres premisas:

- "Los clientes empiezan por decidir el producto, y después deciden la marca"10.

- "Producto es lo que el anunciante fabrica o distribuye y en definitiva, lo que ofrece a los consumidores. M arca es lo que los consumidores compran, va más allá de la propia materialidad del producto"11. Ello se explica por el hecho que la marca ofrece una realidad material, denominada "identidad de marca" y además una realidad psicológica - la llamada "imagen de marca"12.

- "Un producto es algo que se produce en la fábrica; una marca es algo que compra el cliente. Un producto puede ser copiado por un competidor, la marca es única. Un producto puede quedar rápidamente obsol eto; la marca de éxito pervive en el tiempo"13.

${ }^{10}$ Gerber (2006) p. 209.

11 Garcia UCEDA (2001) p. 71.

12 "Identidad de marca" es "el conjunto de atributos, características o significados con los que la marca se autoidentifica y autodiferencia de las demás. Las organizaciones desarrollan estrategias de identidad de marca, que les permitan establecer los parámetros básicos de comunicación y actuación de la marca".

Por su parte, la "imagen de marca" es "la estructura mental (u opinión) que de ella tienen sus públicos, y la integran el conjunto de atributos o significados que los públicos utilizan para identificar y diferenciar a esa marca de las demás".

Así, "la identidad de marca es lo que esta pretende ser, y la imagen de marca es cómo los individuos la perciben. El objetivo de cualquier marca es que su imagen (como los públicos la perciben) sea lo más parecida posible a su identidad". Garrido (2008) p. 365.

${ }^{13}$ KING, Stephen, W PP Group, Londres, citado por Aaker (1994) p. 1. 
Con estas citas queda claro que un producto debería comercializarse siempre bajo el resguardo de una marca; de otra manera se estaría desperdiciándose la ventaja competitivo que entrega el uso exclusivo del signo distintivo.

A continuación, examinaremos brevemente algunos detalles del concepto de diferenciación para luego concentrarnos en el estudio más jurídico y práctico de la distintividad.

\section{ALGUNAS NOCIONES SOBRE DIFERENCIACIÓN}

La diferenciación de un producto puede lograrse a través de determinados elementos, tales como la publicidad, el empaque, el diseño y la calidad del producto. Sin embargo, la base indispensable de la diferenciación es la marca; sin marca no hay diferenciación.

En el ámbito económico y del marketing, se utiliza con gran frecuencia la expresión "diferenciación". Así Kotler se refiere a este concepto de la siguiente forma: "Supóngase que una empresa investigó y eligió el mercado deseado. Si es la única que atiende a dicho mercado, quizá podrá fijar un precio que le genere una ganancia razonable. Si establece un precio demasiado alto y no existen barreras consi derables de entrada, la competencia entrará a este mercado y hará bajar el precio. Si varias empresas apuntan hacia este mercado meta y sus productos no están diferenciados entre sí, casi todo el público preferirá la marca menos costosa y las demás empresas tendrán que bajar los precios. El único camino que le queda a la primera empresa es diferenciar su oferta del producto de la competencia. Si logra hacerlo con eficacia, podrá fijar un precio más alto. La diferenciación permite a la empresa obtener una ganancia extra con base en el valor adicional que perciben los consumidores"14.

De ahí queda claro que la diferenciación surge como una necesidad para las empresas en un mercado con muchos actores. En efecto, a mayor número de competidores mayor será la necesidad de diferenciación. Dicha regla es confirmada por Lambin, cuando sostiene que "Ia diferenciación es un concepto que estriba en la diversidad de la oferta", distinguiendo al respecto dos niveles: a) diferenciación "entre competidores para un mismo tipo de producto," y b) diferenciación "entre los productos de un mismo fabricante propuestos en diferentes segmentos" 15 .

$\mathrm{N}$ aturalmente en un contexto histórico, esa necesidad de diferenciación emerge en los tiempos actuales con una fuerza nunca antes vista, dado que en los mercados globales intervienen un sinnúmero de productos idénticos o similares que para el consumidor son difíciles de evaluar y comparar entre sí. En ese entorno de hipercompetividad surge el lema "diferenciarse o morir". En efecto, ya hace un tiempo se ha publicado un libro con ese título en el cual se constata un "incréble aumento de la oferta de productos en todos los sectores. Se entiende que en EE.UU . hay más de un millón de productos estándar disponibles para ser comprados. En un solo supermercado hay unos 40.000. Pero... la familia media satisface todas sus necesidades con unos 150 de esos productos estándar disponibles en los supermercados. Esto significa que hay bastantes probabilidades de que 39.850 sean absolutamente

\footnotetext{
14 Kotler (1996) p. 293.

15 Lambin (1995) p. 194.
} 
ignorados"16. Esa explosión de opciones de compra ha significado que el consumidor se enfrenta a la tiranía de la elección, terminando confundido, sobreestimulado y finalmente saturado por una oferta improcesable de productos, y el bombardeo incesante de publicidad. Pese a todo ello, el mismo autor subraya que "Ias alternativas son la materia prima de la toma de decisiones; y las decisiones hay que tomarlas". Para ello, reivindica la necesidad de diferenciación, pues sicológicamente "las diferencias intensamente diferenciadas que están ligadas a un producto pueden potenciar la memoria porque pueden ser apreciadas intelectualmente. En otras palabras, cuando se anuncia un producto, se debe dar al consumidor la razón para elegir ese producto"17.

\section{NOCIONES GENERALES SOBRE DISTINTIVIDAD}

Lo usual es que el término "distintividad" se use en el sentido de requisito de registro de la marca; no obstante existen las acepciones como función y característica de la marca. Así por ejemplo, son diversos los tratados que consagran el carácter distintivo de la marca ${ }^{18}$.

También la doctrina es uniforme en el sentido de reconocer la relevancia distintiva de las marcas. "El poder o carácter distintivo de un signo es la capacidad intrínseca que tiene para poder ser marca"19, permitiendo la identificación del origen empresarial del producto o servicio respectivo. "La función distintiva de los signos marcarios es el fundamento de su existencia como tales. Sin posibilidad de distinguir, la marca deja de ser tal"20.

Algunos autores han establecido que la noción de "carácter distintivo" es equivalente a "notoriedad"21, tesis que es rechazado por otros, argumentando que se incurriría en una confusión con las marcas notoriamente conocidas22. Dicha aprensión compartimos plenamente, puesto que la distintividad es característica y el emento esencial de toda marca.

Por su parte, la jurisprudencia se ha referido a la materia de la distintividad, al se ñalar que "la característica de distintividad es fundamental que reúna todo signo para que sea susceptible de registro como marca; lleva implícita la posibilidad de identificar unos productos o unos servicios de otros, haciendo viable de esa manera la diferenciación por parte del consumidor. Es entonces distintivo el signo cuando por sí solo sirva para diferenciar un producto 0 un servicio sin que se confunda con él o con sus características esenciales o primordiales" 23.

Por nuestra parte, definiremos distintividad de la siguiente forma: es la capacidad de un signo para individualizar y diferenciar determinados productos o servicios de una

\footnotetext{
16 Trout (2001) p. 2.

17 Trout (2001) pp. 11-12.

${ }^{18}$ Así, el Convenio de París para la Protección de la Propiedad Industrial (art. 5 C 2; art. 6 quinquies, B 2) y el Acuerdo sobre los Aspectos de Propiedad Intelectual relacionados con el Comercio (art. 15 apartado 1).

19 Otamendi (2010) p. 25.

20 Porcel (2005) p. 37.

${ }^{21}$ FernÁNDEZ-Novoa (1990) p. 78.

22 Gómez Segada (1995) p. 194.

${ }^{23}$ Eternit Colombiana S.A. con La N ación Colombiana a través, de la D ivisión de Signos D istintivos de la Superintendencia de Industria y Comercio de Colombia (2007): Tribunal de Justicia de la C omunidad Andina.
} 
empresa de los de otros competidores. Indudablemente incide en esa capacidad, el uso que se le da a la marca y ese uso estará regularmente referido a los productos o servicios a los que va a identificar. D e esta forma, hay que tener en cuenta que para calificar el carácter distintivo de un signo concreto, es necesario evaluar el signo en relación:

- a la cobertura de productos o servicios para el que ha sido solicitado,

- al público que habitualmente consume o use dichos productos o servicios, y

- a los demás signos existentes, apreciando la existencia de posibilidades de confusión.

El rol fundamental de la distintividad con respecto a las marcas queda al descubierto al tener presente que estas también son Ilamadas "signos distintivos". Signos no distintivos serían entonces aquellos que no poseen un carácter distintivo, es decir que "no sirven para cumplir el fin propio de una marca comercial que es el distinguir un origen empresarial de un determinado bien o servicio" 24 . Comúnmente se consideran desprovistos de distintividad, las siguientes expresiones:

a) Signos genéricos: son aquellos que utilizan el nombre propio de un producto o servicio, para designarlo, de manera que coinciden con el término que generalmente identifica dicho producto o servicio en el lenguaje común. "D efinen no directamente el objeto en causa, sino la categoría, la especie o el género, a los que pertenece el objeto" 25. Como ejemplos, pudiéramos mencionar los signos "(El) Diario", "Zapatillas", "M anzana" para identificar un diario, zapatillas y manzanas, respectivamente. En cambio, la denominación "Apple" sí es marca registrada, no por ser un término en idioma extranjero, sino por identificar artículos electrónicos e informáticos, es decir corresponde a una cobertura ajena a la fruta manzana.

b) Signos indicativos o descriptivos: algunos sectores de la doctrina los tratan como dos categorías independientes; sin embargo, siguiendo la corriente mayoritaria preferimos englobarlos en una sola clase. Son aquellos que entregan al público información sobre características, cualidades u otros antecedentes esenciales del producto o servicio que identifican. Frecuentemente llegan a referirse en forma expresa al rubro al cual pertenece el producto o servicio respectivo. Ejemplos de esta clase de signos constituyen: "U Itrasoft" para papel higiénico, "D ulce" para alimentos dulces, como el chocolate, "Graneado" para arroz, "Vitamínico" para alimentos, o "Algodón" para ropa.

En nuestro ordenamiento jurídico, son expresiones que hacen referencia a la naturaleza, destinación, peso, valor o cualidad de los productos y servicios que desean identificar. Así la jurisprudencia ha distinguido signos descriptivos o indicativos de cualidad, como por ejemplo "O ptima" o "Finissima"; signos descriptivos o indicativos de destinación26, como por ejemplo "Súper Perro" para alimentos de animal y "Banco Inversión", para dis-

\footnotetext{
24 Instituto Nacional de Propiedad Industrial (2010) p. 160.

${ }^{25}$ Mathely (1984) p. 92.

${ }^{26} \mathrm{M}$ arcas descriptivas de destinación, son "aquellas que señalan la forma de utilización de un producto o servicio, pero también pueden señalar la forma de aplicación o la función de los productos o servicios". Instituto NacioNaL de Propiedad Industrial (2010) p. 175.
} 
tinguir negocios financieros ${ }^{27}$; signos descriptivos de peso o medida ${ }^{28}$, como por ejemplo "M ás Salud" para productos farmacéuticos, y la marca "Citric, 100\% exprimido"; signos descriptivos de valor ${ }^{29}$, como por ejemplo "Vuelosbaratos"; y signos descriptivos de origen, nacionalidad o procedencia, como por ejemplo nombres de países, regiones, ciudades u otros lugares geográficos.

Tanto la doctrina como la jurisprudencia, en muchas ocasiones han destacado la dificultad de diferenciar entre signos descriptivos que no son registrables y las marcas evocativas, que sí lo son. Al respecto, prácticamente todos las opiniones coinciden con O tamendi, quien dilucida el asunto en los siguientes términos: "Los signos evocativos dan una idea de cuál es el producto o servicio en cuestión o sobre sus componentes o características. A veces más que una idea se trata de una certeza, y esto es lógico puesto que, de lo contrario, la marca sería engañosa. El signo descriptivo también designa estas mismas características, funciones, destino, origen, calidad, componentes, etc. La diferencia está en que la designación descriptiva es la necesaria o usual para aquello que se describe. La evocativa siempre tendrá en su conformación algún elemento que la hará, en menor o mayor grado, de fantasía. Al concederse una marca evocativa no se quita del dominio público ninguna palabra que se use para describir característica alguna de productos o servicios. No sucede lo mismo si se registrase una designación descriptiva"30.

c) Signos de uso común son "las designaciones que habitualmente se utilizan para un producto, además de las necesarias. Es aquí donde se incorporan las palabras extranjeras... y otras palabras inventadas que adquieran una cierta popularidad en su uso"31. Para entrar en dicha categoría, muchas legislaciones entre ellas la chilena, exigen que el uso de la expresión sea generalizado en el comercio; excluyendo otros ámbitos de la vida. En esta categoría se incluyen especialmente las expresiones que en tiempos pasados fueron marcas registradas, pero cuyo uso se ha popularizado de tal manera de transformarse en la denominación de categoría. Profundizaremos más adelante sobre este tema, oportunidad en que entregaremos varios ejemplos.

A estos casos ampliamente reconocidos, se deberían sumar también las marcas muy simples o las demasiado complejas. Las primeras comprenden "elementos que no poseen nada que las pueda di singuir 0 ... elementos básicos que son partes componentes de otros si gnos y expresiones" 32 . También pudiéramos incluir en dicha categoría a los signos consistentes en una sola letra, número, símbolos de internet (@, www, e-, nombres de dominio TLD), signos ortográficos y otros de un solo carácter. Por otro lado, tampoco tendrían capacidad distintiva, los signos muy extensos, como sería la pretensión de proteger una frase larga completa o un fragmento de un poema o canción.

\footnotetext{
${ }^{27}$ Iglesias (2003) pp. 64-65.

${ }^{28} \mathrm{M}$ arcas descriptivas de peso "consisten en aquellas denominaciones que señalan una cantidad o proporción". Instituto Nacional de Propiedad Industrial (2010) p. 177.

$29 \mathrm{M}$ arcas descriptivas de valor "consisten en expresiones que señalan aspectos del precio de un producto 0 servicio. ... estas denominaciones pueden consistir en referencia comparativa a la calidad de los productos o servicios, como por ejemplo, extra, mejor, más barato". Instituto Nacional de Propiedad Industrial (2010) p. 178.

30 Otamendi (2010) p. 72-73.

31 Otamendi (2010) p. 72.

32 Instituto Nacional de Propiedad Industrial (2010) p. 160.
} 


\subsection{La Relación entre Distintividad y Uso}

En el derecho comparado (países de la U nión Europea, EE.UU ., países del Pacto Andino, Argentina, etc. ), lo normal es que se exige el uso efectivo y real de la marca, sea como requisito para la concesión del registro, su mantención y/o su renovación. También se dan casos en que el uso constituye requisito para interponer oposiciones, o acciones por infracción de marcas. En general, en caso de falta de uso efectivo de una marca registrada, por un tiempo prolongado, generalmente 5 años, se procederá a la cancelación o caducidad del registro respectivo ${ }^{33}$, de modo que la marca quedaría liberada y podría volver a ser solicitada por su antiguo titular o un tercero.

La normativa chilena no establece la obligatoriedad del uso de la marca. El único intento de introducirla a nuestra ley se configuró en el proyecto de la ley $n^{\circ} 19.996$, con la siguiente fundamentación: "A fin de asegurar la correcta concreción de la naturaleza de los signos marcarios, y por ende, la indisolubilidad entre marca, objeto a distinguir y mercado, se ha contemplado la caducidad de las marcas por falta de su uso real y efectivo en el territorio nacional por parte del titular registral o de un tercero con su consentimiento. Esta institución busca impedir el bloqueo del sistema de protección marcaria producto de la saturación registral de meros derechos formales. Para ello se impone al titular registral la carga de hacer uso de su signo, con el objeto de garantizar que todo registro cuente con un producto o servicio efectivamente transado en el mercado, sin perjuicio de que existan causas válidas que justifique el no uso de la misma"34. Pese a esta fundamentación certera contenida en el proyecto original, la idea no tuvo frutos debido a consideraciones constitucionales.

D esde un punto de vista de la pureza del sistema marcario y reafirmando los pasajes del mensaje antes citados, resulta coherente exigir el uso real y efectivo de las marcas, con el fin de:

- evitar la existencia de marcas que ya no tengan capacidad distintiva,

- evitar la especulación habitual de marcas sin fines comerciales genuinos propios, lo cual lleva a una proliferación de solicitudes y registros marcarios,

- despejar el campo para el uso efectivo y real de marcas que sean necesarias,

- mejorar la competitividad entre los agentes económicos y evitar prácticas desleales,

- cumplir con la característica, función y naturaleza esencial de las marcas, esto es distinguir productos y servicios (sin uso no hay distintividad ni diferenciación) ${ }^{35}$.

\footnotetext{
33 La caducidad del registro marcario es una sanción, que deviene como consecuencia gravosa de no haberse cumplido una carga por su titular.

34 M ensaje 4-341 del Presidente de la República con el que inicia un proyecto de ley que modifica la Ley $n^{\circ}$ 19.039, Santiago, 4 de octubre de 1999, p. 11.

$35 \mathrm{Al}$ respecto, resultan muy concluyentes las palabras de M arcos M orales: "L a marca comercial es una institución jurídica que asocia un signo con productos o servicios determinados y que tiene por objeto distinguir estos últimos de otros análogos en el mercado, con lo cual ya en su definición se advierte su vocación de uso. En este sentido, una marca que no es usada no cumple su función propia y puede terminar siendo un subterfugio de papel destinado a entorpecer la competencia mercantil". Morales (2010).
} 
En el último tiempo han aumentado las voces que reconocen la necesidad de introducir el requisito de uso de la marca registrada a nuestra legislación. Así, recientemente la Asociación Chilena de Propiedad Intelectual ha propuesto regular la obligatoriedad de uso de la marca, cancelación de oficio, acción de cancelación y causales de justificación de falta de uso ${ }^{36}$.

No obstante, tiene que tenerse presente que un sistema con requisito de uso complicaría especialmente determinado tipo de marcas (que no tienen un fundamento jurídico), tales como las marcas de reserva ${ }^{37}$ y las ofensivas, defensivas o de protección ${ }^{38}$, las cuales se solicitan por razones de estrategia competitiva, pero sin ser destinadas a un uso posterior.

\subsection{LA Distintividad, Un CONCEPTO DinÁmico}

C abe resaltar que la distintividad es un concepto dinámico en el tiempo y gradual en cuanto a su intensidad. En otras palabras, un mismo signo puede estar expuesto a variaciones temporales en lo que a su grado de distintividad se refiere, e igualmente existen signos más o menos distintivos que otros.

El análisis del dinamismo o variabilidad de la distintividad conlleva automáticamente a relacionar ese concepto con el uso de la marca. Con una finalidad de orden, abordaremos este punto enfocándonos en dos cuestiones puntuales:

1.- ¿Cuál es el momento y el tiempo durante el cual debe estar presente el requisito de la distintividad?

2.- ¿Cuál es el grado de distintividad que debe exigirse a fin de conceder o mantener el registro marcario?

1.- En principio, podemos sostener que la distintividad irradia sus efectos más allá de la obtención del registro; y debería persistir durante toda la vida de la marca como requisito de conservación del registro. Profundizando al respecto, existen diversos momentos para exigir el cumplimiento de la condición de distintividad. En primer lugar, la marca debe poseer distintividad en el momento de solicitarse. En efecto, el signo a registrar "debe tener unos niveles de distintividad suficientes que le permita ser distinguido de

\footnotetext{
36 Asociación Chilena de Propiedad Intelectual (ACH IPI), Informe "Propuestas de M odificaciones L ey de Propiedad Industrial, M arcas Comerciales". Sin perjuicio, el tema del uso obligatorio de la marca sigue siendo un tema controvertido, incluso entre los mismos asociados de la AC HIPI.

$37 \mathrm{M}$ arcas de reserva "se encuentran regi stradas con el fin de ser utilizadas con su propósito distintivo a partir de un plazo, determinado o no, posterior a tal registro". Bertone y Cabanellas de las Cuevas (2008 I) p. 272.

$38 \mathrm{M}$ arcas defensivas "son las registradas no con el propósito de utilizarlas para identificar productos o servicios, sino con el fin de impedir que otros puedan utilizarlas, protegiéndose aś la capacidad distintiva de ciertas marcas que sí son utilizadas comercialmente".

- M arcas ofensivas "son las que tampoco tienen por propós to inmediato su utilización como signos distintivos, sino impedir o dificultar el registro o la utilización de signos marcarios por un tercero que es el verdadero interesado en su uso". La doctrina también las conoce bajo el nombre de "marcas similares 0 alternativas".

"M ientras que las marcas defensivas tienen por propósito asegurar y perfeccionar la tutela de otras marcas del mismo titular, las ofensivas están destinadas a trabar 0 anular los derechos de otros titulares 0 interesados en ciertas marcas". Bertone y Cabanellas de las Cuevas (2008I) p. 270.
} 
otro, y que permita individualizar los productos o servicios que identifique de otros existentes en el mercado" 39. En caso de no satisfacerse esta exigencia al solicitarse el signo, este no será registrable por incurrir en una causal de irregistrabilidad. Así, lo establecen uniformemente los tratados y el derecho comparado: el Convenio de París para la Protección de la Propiedad Industrial (art. 6 quinquies, B 2), la Directiva Europea sobre M arcas (art. 3.1 letra b), el Reglamento sobre la marca comunitaria (art. $7 n^{\circ} 1$ b), la Ley española de marcas (art. $5 n^{\circ} 1$ b), el Código de Propiedad Intelectual de Francia (art. L 711-3), la Ley alemana de marcas ( $\S 8(2) n^{\circ} 1$ ). Estos cuerpos legales, reforzado por una doctrina uniforme, impiden la apropiación de signos carentes de distintividad.

En Chile, se contempla al respecto la causal de irregistrabilidad de la letra e) del artículo 20 de la Ley de Propiedad Industrial40. En relación a esa norma legal, cabe mencionar aquí que recientemente se ha presentado un proyecto de ley para modificarla, con el objeto de restringir la amplitud excesiva de la causal de irregistrabilidad contenida en las expresiones "que no presente carácter distintivo", y evitar así criterios dispares en la aplicación de esta locución 41 .

U na vez registrada la marca, esta debería conservar en nuestro país su fuerza distintiva al menos durante los primeros cinco años de vida del registro, toda vez que durante ese lapso se encuentra pendiente el plazo para interponer la acción de nulidad marcaria por alguna de las causales de irregistrabilidad establecidas por la ley, entre las cuales se encuentra la letra e) antes referida.

La conservación del carácter distintivo más allá del plazo indicado no sería necesario, y solo sería lógico y coherente en un sistema jurídico que exigiera el uso del signo como requisito de su conservación y/o renovación, pues solo de esa forma se vigilaría efectivamente el cumplimiento de este requisito.

2.- En lo relativo a la problemática de la intensidad o grado de distintividad que debe poseer un signo para ser admitido a registro, también esta puede sufrir variaciones, básicamente debido a dos factores:

- el tipo de marca influye directamente en la capacidad distintiva, y

- el uso que se le da a la marca en cuestión.

$\mathrm{H}$ ace ya un tiempo que la doctrina ha abierto una clasificación que distingue entre marcas fuertes y marcas débiles, según la intensidad de la fuerza distintiva. Así, marcas débiles son "aquellas que se encuentran solamente protegidas contra la imitación total". En cambio, las marcas fuertes se definen "como aquellas que son protegi das mucho más in-

\footnotetext{
39 BARREDA (2009) pp. 213-214.

40 Estas se encuentran establecidas en la Ley 19.039 sobre Propiedad Industrial:

Artículo 20.- "No podrán registrarse como marcas: e) Las expresiones 0 signos empleados para indicar el género, naturaleza, origen, nacionalidad, procedencia, destinación, peso, valor o cualidad de los productos, servicios 0 establecimientos; las que sean de uso gen eral en el comercio para designar cierta clase de productos, servici os o establecimientos, y las que no presenten carácter distintivo o describan los productos, servicios 0 estableci mientos a que deban aplicarse".

41 Proyecto de ley que modifica el artículo 20 letra "e" de la ley n 19.039, de propiedad industrial, Boletín N ${ }^{\circ}$ 7250-03.
} 
tensamente, llegando a prohibirse todas las marcas que incluyan modificaciones y variaciones que dejan persistir la identidad de la marca que se desea tutelar" 42. Tal como se reconoce por Bertone y $\mathrm{C}$ abanellas, es evidente que no existe una clara línea divisoria entre ambas clases de marcas, de manera que la calificación en una u otra categoría es bastante relativa y el paso de una a otra, gradual.

En base a esta clasificación, dichos autores establecen una interesante correlación que nos permitimos de complementar con aportes propios: a mayor grado distintivo de un signo, mayor será el poder para que el titular pueda ejercer su derecho de uso de la marca, y para excluir a terceros del uso de dicho signo, sea en forma íntegra o de sus componentes. En efecto, una marca fuerte tendrá un mayor ámbito de uso exclusivo que una marca débil, y con ello aumentará también su exclusividad e identidad frente al público. Evidentemente, se crea un círculo virtuoso para el titular de la marca, basado en que lo monopolizable crea valor diferenciador en el mercado. En el fondo todo se inicia con la decisión de buscar un signo que pueda desembocar en una marca fuerte, y tienen una alta probabilidad de convertirse en marca fuerte, los signos imaginativos, también conocidos como "palabras sin contenido conceptual"43, estas son "las voces de fantasía, inexistentes en los dicci onarios, e inventadas libremente, que no son nombres propios" 44 . D esde el punto jurídico, se trata de signos recomendados por el abogado para su registro, pues carecen de sentido, poseen un alto grado de distintividad; y por consiguiente será relativamente sencillo de que pasen el examen de fondo de la autoridad marcaria y al mismo tiempo, más fácil y sólida será su defensa en caso de conflictos marcarios (juicios de oposición o de nulidad).

Sin embargo, por el otro lado, los encargados de marketing, publicidad y ventas de las empresas no suelen compartir el criterio jurídico, pues generalmente siguiendo objetivos de estrategia comercial, prefieren marcas que tengan un carácter más indicativo, descriptivo o evocativo, dado que estas, al existir cierto nexo entre el signo y el producto (cobertura de la marca), permiten instalarse con mayor facilidad en la mente del público, y en consecuencia no requieren elevados esfuerzos y gastos publicitarios iniciales. Sin ir más allá, en la reconocida obra "Fundamentos de M arketing" se recomienda escoger como marca aquel nombre que sugiere "algo acerca del producto, sobre todo sus beneficios y empleo"45.

Este contrasentido entre el pensamiento jurídico y el económico-comercial se produce debido a que cada uno de estos profesionales percibe únicamente su respectiva esfera en el tema de las marcas, ignorando muchas veces el funcionamiento de las marcas en el otro ámbito. Con ello confirmamos la importancia de integrar los conocimientos jurídicos

\footnotetext{
42 Bertone y Cabanellas de las Cuevas (2008 I) p. 257-258.

${ }^{43}$ Se trata de una terminología utilizada por Ley argentina de $M$ arcas, al establecer en su artículo $1^{\circ}$ : "Pueden registrarse como marcas para distinguir productos y servicios: una o más palabras con o in contenido conceptual; los dibujos, los emblemas; los monogramas; los grabados; los estampados; los sellos; las imágenes; las bandas; las combinaciones de colores apli cadas en un lugar determinado de los productos o de los envases; los envoltorios; los envases; las combi naciones de letras y de números, las letras y números por su dibujo especial; las frases publicitarias, los relieves con capacidad distintiva y todo otro signo con tal capacidad".

44 Bertone y Cabanellas de las Cuevas (2008 I) p. 328.

45 Stanton et al. (2000) p. 267.
} 
y económico-empresariales sobre esta materia, sin descuidar la perspectiva ajena a su profesión.

Por otro lado, independientemente de tratarse de una marca débil o fuerte, reiteramos que la distintividad de un signo también es influenciada por el uso que se le da al mismo; tema que trataremos en unas líneas más. En definitiva, podemos observar una estrecha interrelación entre el carácter distintivo, el registro de la marca y su uso. Gráficamente, esto puede ser ilustrado de la siguiente forma:

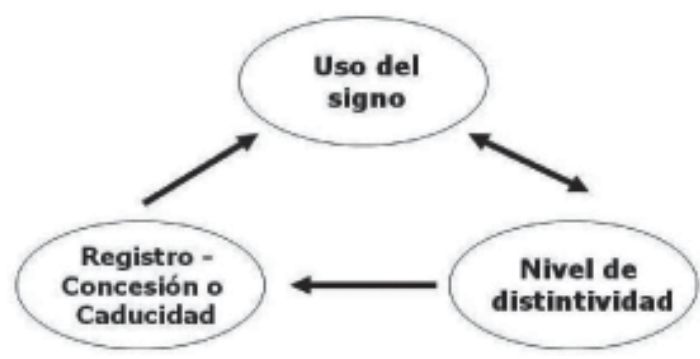

A continuación veremos de qué forma esta interrelación opera aumentando o disminuyendo el grado de distintividad.

\subsubsection{Fortalecimiento de la distintividad por el uso}

En principio se establece que las denominaciones y signos genéricos, así como las palabras que son de uso general y común con respecto a los productos o servicios a los cuales se refieren, carecen de distintividad, y por lo tanto no son registrables. Sin embargo, esos signos pueden Ilegar a adquirir distintividad a través de un uso prolongado y consistente en el mercado, de manera que el público que habitualmente consume o use el producto, Ilegue a identificar la marca con un determinado origen empresarial. Esto es el caso del Ilamado "secondary meaning", denominado en español, "distintividad sobrevenida" o "distintividad adquirida", y definido como "un fenómeno, que implica mutaciones semánticas o simbólicas, en virtud del cual un signo originariamente desprovisto de capacidad distintiva, por consecuencia fundamentalmente del uso, a los ojos de los consumidores se convierte en identificador de los productos o servicios de un determinado empresario" 46.

El efecto de la "distintividad adquirida" consiste en el "permiso" excepcional que la ley otorga al interesado para que este pueda proteger un signo en principio irregistrable, mediante la obtención de un registro marcario. Esta institución se encuentra consagrada en el Acuerdo sobre los ADPIC (art. 15.147), y de ahí fue adoptada como estándar mínimo obligatorio por los países miembros de la O rganización M undial de Comercio: la D irectiva Europea sobre M arcas (art. 3.3), el Reglamento sobre la marca comunitaria (art.

\footnotetext{
46 Gómez SEGADa (1995) pp. 181-182.

47 Expresa el artículo 15.1 del Acuerdo sobre los Aspectos de los D erechos de Propiedad Intelectual relacionados con el Comercio: "Cuando los signos no sean intrínsecamente capaces de distinguir los bienes o servicios pertinentes, los M iembros podrán supeditar la posibilidad de registro de los mismos al carácter distintivo que hayan adquirido mediante su uso".
} 
$7 n^{\circ} 3$ ), la Ley española de marcas (art. $5 n^{\circ} 2$ ), el Código de Propiedad Intelectual de Francia (art. L711-2 frase final), la Ley alemana de marcas (§ 4 (2)), etc.

En Chile, la institución del "secondary meaning" obtuvo reconocimiento legal a partir de la ley 19.996 del año 2005. Así, el artículo 19 de la ley de propiedad industrial, en su versión modificada establece: "Cuando los signos no sean intrínsecamente distintivos, podrá concederse el registro si han adquirido distintividad por medio del uso en el mercado nacional".

Para los efectos de nuestro estudio, y en base a lo anterior, resulta interesante recordar la clasificación de la distintividad que puede poseer un signo marcario48:

a) distintividad originaria, intrínseca 0 abstracta, que sería aquella inherente al signo por no relacionarse con signos genéricos, indicativos, descriptivos o de uso general. La regla general de las marcas registradas posee este tipo de distintividad.

b) distintividad adquirida, es la que se ha obtenida por el uso durante un tiempo suficientemente extenso, de manera que el público logre identificar el signo asociado a un producto o servicio determinado. Se trata de casos excepcionales considerando el universo de las marcas registradas.

A estas dos categorías, la doctrina ha agregado una tercera:

c) distintividad extrínseca o concreta: "es aquella que se relaciona con la existencia de otros signos similares o idénticos con anterioridad" 49 .

\subsubsection{El debilitamiento de la distintividad por el uso}

La marca una vez registrada, también puede experimentar un debilitamiento, o incluso la pérdida completa de su capacidad distintiva, fenómeno que ha recibido por parte de la doctrina distintas denominaciones, pero que en definitiva se refieren todas a lo mismo: vulgarización ${ }^{50}$, dilución ${ }^{51}$ o licuación, banalización ${ }^{52}$, genericidio ${ }^{53}$ o degeneración.

Sobre este tema, Otamendi expresa en forma general que "un signo no goza de poder identificatorio cuando el consumidor al percibir una palabra sin poder distintivo no podrá saber a qué producto se refiere o cuál origen tiene el bien que proyecta adquirir" 54 .

\footnotetext{
${ }^{48}$ El autor español Gómez Segada utiliza una terminología levemente diferente para referirse a esta clasificación. Así señala que "por lo que se refiere a su fuerza distintiva, los signos pueden ser inherentemente distintivos y no inherentemente distintivo". Gómez Segada (1995) p. 191.

49 Instituto Nacional de Propiedad Industrial (2010) p. 152.

50 La "vulgarización" se da "cuando una marca debido a su mal uso pierde su capacidad distintiva y se confunde con el producto mismo que distingue (la marca se come al producto); es decir la marca se tran forma en la forma habitual que los consumidores nombran el producto". Proyecto de ley que modifica el artículo 20 letra "e" de la ley $n^{\circ} 19.039$, de propiedad industrial, Boletín $N^{\circ}$ 7250-03.

${ }^{51}$ La "dilución de marca" es el "cercenamiento gradual o la dispersión de la identidad de marcas notorias o renombradas en la mente del público, por su uso en productos no competitivos". Otamendi (2010) p. 25.

52 "Banalización" "supone un proceso gradual en cuyo desarrollo permaneció inactiva la voluntad del titular" de un signo originariamente distintivo. Bertone y Cabanellas de las Cuevas (2008 II) p. 77.

53 "G enericidio" es un término que se ha utilizado por primera vez en una sentencia de la Corte Suprema de EE.UU en 1983, para describir un "proceso a través del cual una expresión marcaria se convierte en un nombre genérico para una categoría entera de productos". Artículo "genericide". Disponible en: «tttp://www.wordspy. com/words/genericide.asp>

${ }^{54}$ Otamendi (2010) p. 25.
} 
Las consecuencias de esta merma de distintividad son variadas. En un plano económico, se traduce en la pérdida de valor comercial de la marca en cuestión, puesto que se llega a confundir en lugar de diferenciar el producto o servicio. En el contexto jurídico, los efectos dependerán de la legislación aplicable, como veremos más adelante.

Podemos sostener que en principio toda marca aspira a la fama ..., pero ser demasiado famoso no puede ser deseable. Es lo que un artículo periodístico muy certeramente tituló " $M$ arcas que mueren de éxito" 55 , para referirse a signos, que inicialmente con poder identificatorio del producto o servicio, han devenido en un genérico, simplemente llegaron a ser denominaciones de categoría del producto o servicio.

Algunas de estas marcas llegan a ser tan famosas que incluso son incorporadas en los diccionarios. Presentamos a continuación algunos ejemplos, transcribiendo su significado según el D iccionario de la Lengua Española de la Real Academia Española56:

- Gillete o Gillette (D e K. C. Gillette, 1855-1932, industrial estadounidense que la inventó; marca reg.)

f. $\mathrm{H}$ oja de afeitar desechable.

Se incluyó el año 2001 en el diccionario.

- Plastilina (M arca reg.)

f. Sustancia moldeable, de diversos colores, que se utiliza en escultura y como material educativo.

- Teflón (D el ingl. Teflon, marca reg.)

m. M aterial aislante muy resistente al calor y a la corrosión, usado para articulaciones y revestimientos así como en la fabricación de ollas y sartenes.

- Jacuzzi (Voz ingl., marca reg.)

m. Bañera para hidromasaje.

- Ping-pong (Voz ingl., marca reg.)

$\mathrm{m}$. Juego semejante al tenis, que se practica sobre una mesa de medidas reglamentarias, con pelota ligera y con palas pequeñas de madera a modo de raquetas.

- Lycra (M arca reg.)

f. Tejido sintético elástico, utilizado generalmente en la confección de prendas de vestir.

- Vaselina (D el ingl. vaseline, marca reg.)

1 f. Sustancia crasa, con aspecto de cera, que se saca de la parafina y aceites densos del petróleo y se usa en farmacia y perfumería.

2. f. En el fútbol y otros deportes, disparo suave y de trayectoria muy curva que hace volar el balón por encima de uno o varios jugadores contrarios.

3. $\mathrm{f}$. coloq. Tacto, prudencia o delicadeza en el modo de actuar.

- Klystron (D el ingl. klystron, marca reg.)

\footnotetext{
55 Авајо (2006)

${ }^{56}$ En total aparecen 76 marcas en la 22a edición del D iccionario de la Real Academia Española.
} 
- m. Fís. Tubo electrónico empleado para generar o amplificar microondas en comunicaciones y radares.

- Sintasol (M arca reg.)

m. M aterial plástico utilizado para el cubrimiento de suelos.

- Celofán (D el fr. C ellophane, marca reg.)

m. Película transparente y flexible, que se obtiene por regeneración de la celulosa contenida en las soluciones de viscosa y se utiliza principalmente como envase 0 envoltura.

- Nailon (D el ingl. nylon, marca reg.)

m. M aterial sintético de índole nitrogenada, del que se hacen filamentos elásticos, muy resistentes. Se emplea en la fabricación de géneros de punto y tejidos diversos.

- Termo (D e thermos, marca reg.)

m. Vasija de dobles paredes, entre las que se ha hecho el vacío, y provista de cierre hermético. Sirve para que las sustancias introducidas en la vasija conserven su temperatura sin que influya en esta la del ambiente.

- Rímel (D e rimmel, marca reg.)

m. Cosmético para ennegrecer y endurecer las pestañas.

- Polo (M arca reg.)

m. Tipo de helado que se come cogiéndolo de un palillo hincado en su base.

Estos casos se han hecho ya tan comunes que el propio D iccionario de la Lengua Española, incorpora entre las Advertencias para su uso, la siguiente nota: "2.8. M arcas registradas Las marcas regi stradas cuyo empleo como sustantivos comunes así lo recomienda se recogen en el Diccionario haciendo constar su condición de tales, de acuerdo con la legislación vigente, en el paréntesis etimológico.- Si alguna entrada correspondiente a una marca registrada no presentara esta información, la empresa que la comercializa podrá dirigirse a la Real Academia Española para solicitar el cambio oportuno en la próxima edición del D iccionario".

Por su parte, el Reglamento sobre la marca comunitaria prevé el caso en su artículo 10 subtitulado "Reproducción de la marca comunitaria en diccionarios", estableciendo:

"Si la reproducción de una marca comunitaria en un diccionario, una enciclopedia o una obra de consulta similar diere la impresión de que constituye el término genérico de los bienes o servicios para los cuales está registrada la marca, el editor, a petición del titular de la marca comunitaria, velará por que la reproducción de esta vaya acompañada, a más tardar en la siguiente edición de la obra, de la indicación de que se trata de una marca registrada".

Normas similares se encuentran también incluidas en la Ley española de M arcas (art. 35), y en la ley alemana de marcas (§ 16). Si bien la sola inclusión del signo marcario en un diccionario, podría interpretarse como una manifestación objetiva de la pérdida del carácter distintivo, cabe concluir en base a estos textos legales, que para perfeccionarse esta, se requiere además de un elemento subjetivo copulativo: que dicha pérdida provenga de la inactividad del titular de la marca. En otras palabras no basta con una sola publicación en el diccionario, sino que esta debe ir acompañada de la omisión del derecho a rectificación. 
En el contexto de las marcas que evolucionan hacia la designación de categoría del producto 0 servicio, 0 tamendi especifica dos pasos independientes:

1) el público comienza a referirse "a un producto designándolo con lo que él cree que es su nombre pero que, en realidad, es una marca".

2) "L os distintos fabricantes del producto designan sus productos en etiquetas y publicidad con la 'marca'".

Continúa señalando ese mismo autor: "así, poco a poco, pero inexorablemente, la marca deja de distinguir un producto para ser su denominación común. Este nombre, signo 0 palabra ya no indicará el origen sino una naturaleza"57.

Surge en forma lógica la interrogante acerca de las causas de la pérdida de distintividad de una marca. Para explicar este punto, la doctrina esboza condiciones intrínsecas del signo escogida 0 causas exógenas al sign $0^{58}$. Por nuestra parte, preferimos distinguir entre causas propias o ajenas al mismo titular de la marca; así por ejemplo, podemos encontrar las siguientes:

- Elección inicial de una marca débil, esto es un signo con escaso poder distintivo, como sería el caso de expresiones o componentes que sean indicativos, genéricos, evocativos o de uso común. También caerían en esta causal las marcas no tradicionales (como por ejemplo, signos de color único, marcas sonoras y las olfativas), y tal como antes descrito, marcas que se componen de números o combinaciones numéricas, o de siglas o combinaciones de pocas letras.

- Ser primer entrante a un nuevo mercado, al introducir un producto o servicio innovador que (por lo menos inicialmente) no tiene competidores. Esa situación que otorga una importante ventaja competitiva e implica una alta participación de mercado, permite construir un liderazgo indiscutido en el mercado ante la ausencia o escasa competencia, y así también crear una marca líder. Sin embargo, en ojos del público puede ser la única marca conocida en su categoría, incluso cuando las empresas seguidoras adopten un producto o servicio similar, de manera que se comience por denominar a los productos de los seguidores por la marca del primer entrante.

- Uso inadecuado del signo por parte del propio titular: esta causal pudiera darse en el caso de extensiones de la marca hacia otros productos o servicios no relacionados con la cobertura original y conocida por el público, 0 en el caso de campañas de marketing y publicidad que diluyan el poder distintivo del signo.

- No renovación del registro marcario, lo cual trae como consecuencia la pérdida de protección del signo y de la exclusividad. Esto puede deberse a una omisión involuntaria del titular o a una renuncia voluntaria. Con ello el signo - muchas veces ya bien conocido por el público- pasa a dominio público, siendo usado como designación genérica.

- U so incorrecto y muchas veces indebido del signo o de signos similares por parte de terceros, pero tolerado por el titular. Ello se refiere a los casos en que personas

\footnotetext{
57 Otamendi (2010) p. 76.

58 Así por ejemplo: Bertone y Cabanellas de las Cuevas (2008 II) p. 77.
} 
que contratan con el titular de la marca en cuestión, tales como licenciatarios o distribuidores, usen la marca de una forma inadecuada, muchas veces incumpliendo las normas gráficas o fonéticas impartidas por el titular. En ese sentido, debe considerarse también dañino el uso de las llamadas marcas genéricas o blancas por parte de los distribuidores. Asimismo, conduce al debilitamiento de la marca, la tolerancia del titular frente al uso o registro de signos similares, cuando estos tengan una cobertura de productos o servicios que sea idéntica o similar a la marca del titular. La intolerancia del titular en estos casos se debería manifestar a través de la interposición de acciones civiles o criminales de infracción de marca si hay uso indebido del mismo signo, o mediante demandas de oposición o de nulidad, en el evento de marcas solicitadas o registradas similares.

\subsection{LA ELECCIÓN INICIAL DE UNA MARCA Y SU USO ADECUADO POSTERIOR}

Para evitar el riesgo del rechazo de una solicitud de marca por falta de distintividad por una parte, y la pérdida de distintividad de una marca ya registrada, por la otra, se deberá poner énfasis en una correcta elección inicial del signo a proteger y luego en su uso adecuado.

En lo relativo a la elección inicial de un signo a proteger, y de acuerdo a lo visto en este trabajo, el consejo más importante debería ser: elegir palabras sin contenido ni significado conceptual, es decir libremente inventadas; estas suelen tener un alto grado de distintividad, y de esta forma, se asegurará un procedimiento fluido y expedito de registro (sin oposición de terceros, ni de la autoridad marcaria), y además se contribuirá a la larga a proteger el negocio ante imitadores marcarios (fácil defensa). En consecuencia, deberían evitarse especialmente marcas descriptivas o indicativas.

Lo anterior ha de entenderse sin perjuicio de las recomendaciones típicas: que el signo sea fácil de leer, escribir, deletrear y de pronunciarse, de fácil memorización, no muy corto, ni muy largo, que no tenga connotaciones negativas en otros idiomas, ni en el propio.

Referente al uso apropiado de la marca registrada a fin de resguardar su distintividad en el tiempo, la O rganización M undial de Propiedad Intelectual ha acuñada algunas reglas:

1.- N o se debe utilizar únicamente la marca para designar el producto, es decir hay que evitar reemplazar la denominación genérica mediante la marca. "Cuando se emplea de forma sistemática la designación del producto, además de la marca, el titular informa de manera inequívoca al público que su marca distingue un producto particular de una determinada categoría. Ello adquiere especial importancia cuando el propietario de la marca ha inventado un producto novedoso que es el único de la categoría en cuestión" . "Cuando en 1938 se inventó el café instantáneo, el primer producto que vendió la compañía inventora se denominó NESCAFÉ. Sin embargo, desde el inicio la compañía adoptó la costumbre de emplear en las eti quetas del producto la designación 'café instantáneo' o 'café soluble".

2.- "La marca debe ser usada como si se tratase de un adjetivo, y nunca como si fuese un sustantivo" o un verbo, o sea que no se podrá emplear el nombre de la marca con un artículo, ni para designar una actividad. Así, por ejemplo "'tres variedades de NESCAFÉ' en vez de 'tres N ESCAFÉS'". 
3.- En la publicidad y en otras partes (empaques, envoltorios, etc.) deberá colocarse la marca de forma destacada, de modo que se distinga nítidamente de los demás elementos. Así pueden utilizarse comillas, negrita y letras mayúsculas para resaltar el signo.

4.- D ebe utilizarse la marca siempre en conjunto con el símbolo de marca registrada ${ }^{\circledR}$, de acuerdo a lo prescrito por la ley. La "función de esas señales consiste en avisar a los competidores que se abstengan de cometer actos que constituyan infracción de la marca" 59.

Con el fin de que estas reglas sean aplicadas en forma uniforme y correcta por el personal de la empresa y por terceros relacionados, conviene que se implementen directrices que plasmen la política de uso de la marca.

\section{CONCLUSIONES}

El rol actual de las marcas en el mundo económico-empresarial sigue siendo clave a la hora de diferenciar los productos y empresas de sus competidores. Así el valor estratégico que desempeñan esos derechos de propiedad industrial ha incluso aumentado ante el nuevo contexto global de la hipercompetitividad.

Un elemento jurídico clave de las marcas es la distintividad, a tal punto que constituye una característica, función y requisito de registro de las marcas comerciales. La capacidad distintiva de un signo otorga identidad al producto o servicio, y permite al consumidor o usuario del mismo conocer su origen empresarial.

Al mismo tiempo, hay que tener en cuenta que la distintividad es un concepto flexible y dinámico en el tiempo, que varía de acuerdo al uso que se le dé al signo marcario. En ese sentido, la forma de cómo se usa el signo condiciona su distintividad, sea para crear, aumentarla o incluso para perderla, lo cual a su vez puede cobrar incidencia en el registro marcario.

Pese a que en Chile el uso de la marca no constituye requisito de obtención, ni conservación del registro marcario, queda claro que en el futuro no se va a poder sustraerse de una tendencia mundial iniciada ya en el Acuerdo sobre los AD PIC. En concordancia con esta circunstancia, resulta que actualmente, la distintividad solo constituye requisito de constitución del registro, y no de conservación del mismo.

Lo anterior no hace sino subrayar la estrecha vinculación existente entre uso de la marca, la capacidad distintiva que por esa vía se predispone, y el registro marcario. Dado que la distintividad actúa como un eslabón esencial en este juego de componentes, conviene que desde el nacimiento de la marca y luego en la etapa de uso posterior, se establezca una clara planificación del signo marcario, que considere cómo debe ser usada la marca escogida, a fin de garantizar un óptimo desempeño del nivel distintivo.

59 Organización Mundial de Propiedad Intelectual (2010) pp. 29-30. 


\section{BIBLIOGRAFÍA CITADA}

Aaker, D avid A. (1994): Gestión del Valor de la Marca: Capitalizar el Valor de la Marca (M adrid, Editorial D íaz de Santos) 332 pp.

Аваjo, Carlos G. (2006): "M arcas que mueren de éxito". Disponible en: «ttp://www. cincodias.com/articulo/Sentidos/M arcas-mueren-exito/20060718cdscdicst_1/> [fecha de consulta: 30 de enero de 2011].

Asociación Chilena de Propiedad Intelectual (ACHIPI), Informe "Propuestas de M odificaciones Ley de Propiedad Industrial, M arcas Comerciales", Informativo para los Asociados n²70/2010, Santiago, 3.11.2010, 12 pp.

BARredA, José (2009): "Algunas anotaciones respecto de los requisitos de registrabilidad de signos según la D ecisión 486 de la Comunidad Andina", en: Morales A., M arcos (edit.), Estudios de D erecho y Propiedad Intelectual, Colección de Trabajos en H omenaje a Arturo Alessandri Besa (Santiago, Editorial Jurídica de C hile) pp. 213-244.

Bertone, Luis Eduardo y Cabanellas de las Cuevas, Guillermo (2008): Derecho de M arcas, Tomo I (Buenos Aires, Editorial H eliasta, $3^{a}$ ed.) 432 pp.

Bertone, Luis Eduardo y Cabanellas de las Cuevas, Guillermo (2008): Derecho de M arcas, Tomo II (Buenos Aires, Editorial H eliasta, $3^{\mathrm{a}} \mathrm{ed}$.) 667 pp.

Fernández-Novoa, Carlos (1990): Derecho de marcas (Madrid, Editorial Marcial Pons) $112 \mathrm{pp}$.

García Uceda, M ariola (2001): Las Claves de la Publicidad (M adrid, Esic Editorial, 5 a ed.) $498 \mathrm{pp}$.

Garrido, Francisco Javier (2008): Lo que se aprende en los mejores M BA, Vol. 2 (M adrid, Editorial Gestión 2000) 704 pp.

Gerber, Michael E. (2006): Las siete disciplinas para crear una empresa competitiva (Barcelona, Editorial Paidós) 518 pp.

Gómez Segada, José Antonio (1995): "Fuerza Distintiva y Secondary Meaning en el D erecho de los Signos D istintivos", Cuadernos de Derecho y Comercio, nํㅜ 16, M adrid, pp. 181-199.

Iglesias M., Carmen (2003): Estudio Jurisprudencial de M arcas y Patentes (Santiago, Editorial LexisN exis) 562 pp.

Instituto Nacional de Propiedad Industrial (2010): M arcas Comerciales - M anual de Procedimi ento (Santiago, Editorial PuntoLex) 372 pp.

Kotler, Philip (1996): Dirección de M ercadotecnia (M éxico, Editorial Prentice Hall, $8^{a}$ ed.) $800 \mathrm{pp}$.

Lambin, Jean-Jacques (1995): M arketing Estratégico (París, Editorial M acGraw-H ill, $3^{a}$ ed.) $610 \mathrm{pp}$.

Mathely, Paul (1984): Le droit francais des signes distinctives (París, JN A editions) 925 pp. Morales A., Marcos (2010) "¿Debiera ser obligatorio el uso de la marca registrada?" D isponible en: <http://derechomarcario.blogspot.com/2010/10/debiera-serobligatorio-el-uso-de-la.html> [fecha de consulta: 30 de enero de 2011] 
Organización Mundial de Comercio: “¿Qué se entiende por derechos de propiedad intelectual?", Disponible en: <http://www.wto.org/spanish/tratop_s/trips_s/intel__s. htm > [fecha de consulta: 30 de enero de 2011]

Organización Mundial de Propiedad Intelectual (2010): Curso “M arcas, diseños industriales e indicaciones geográficas", 10 de marzo a 18 de mayo de 2010, M ódulo II M arcas (Ginebra, W IPO Academy) 50 pp.

Otamendi, Jorge (2010): D erecho de M arcas (Buenos Aires, Ed. Abeledo Perrot, 2010, $7^{\text {a }}$ ed.) $470 \mathrm{pp}$.

Porcel, Roberto J. (2005): M anual de Falsificación Marcaria. Procedimiento Penal. Su especialidad (Buenos Aires, Legis Argentina) 382 pp.

Salis, Eli (2006): "Ley 22.362 Ley de M arcas y Designaciones", en Código de Comercio y normas complementarias. Análisis doctrinal y jurisprudencial (Buenos Aires, Editorial H ammurabi, Tomo 6 Propiedad Industrial) pp. 121-197.

Stanton, W illiam; Etzel, M ichael; Walker, Bruce (2000): Fundamentos de M arketing (M éxico, Editorial M cGraw-Hill $11^{\mathrm{a}} \mathrm{ed}$.) $707 \mathrm{pp}$.

Trout, Jack (2001): D iferenciarse o morir (M adrid, M acGraw-H ill) 210 pp.

\section{NORMAS CITADAS}

\section{Argentina:}

Ley $\mathrm{N} \cong 22.362$, de M arcas. Boletín O ficial, 2 de enero de 1981.

\section{Alemania:}

Ley de marcas (Gesetz über den Schutz von Marken und sonstigen Kennzeichen M arkengesetz) del 25 de octubre de 1994.

\section{Chile:}

D.F.L. $N \cong 3$ que fija el Texto refundido, coordinado y sistematizado de la Ley $\mathrm{N} \cong$ 19.039, de Propiedad Industrial. D iario 0 ficial, 20 de junio de 2006.

Ley 19.996 modifica la ley 19.039 sobre propiedad industrial. Diario 0 ficial, 11 de marzo de 2005.

M ensaje 4-341 del Presidente de la República con el que inicia un proyecto de ley que modifica la Ley $n^{\circ}$ 19.039, Santiago, 4 de octubre de 1999, p. 11. Disponible en: «ttp://www.bcn.cl/obtienearchivo?id=recursoslegales/10221.3/4216/1/H L 19996. pdf $>$ [fecha de consulta: 30 de noviembre de 2010].

Proyecto de ley que modifica el artículo 20 letra "e" de la ley $n^{\circ} 19.039$, de propiedad industrial, Boletín $N^{\circ} 7250-03$, presentado el 5 de octubre de 2010. D isponible en: বhttp://www.camara.cl/pley/pley_detalle.aspx?prmID =7648\& prmBL =7250-03> [fecha de consulta: 9 de diciembre de 2010].

\section{ESPAÑA}

Ley $\mathrm{N} \cong$ 17/2001, de 7 de diciembre, de marcas. Boletín Oficial del Estado de 8 de diciembre de 2001. 
Estados Unidos de AmÉrica:

U.S. Code, Title 15-Commerce and Trade, Chapter 22-Trademarks

Disponible en: বhttp://www.law.cornell.edu/uscode/15/usc_sec_15_00001127----000-. html> [fecha de consulta: 30 de noviembre de 2010].

EUROPA:

Directiva 2008/95/CE del Parlamento Europeo y del Consejo relativa a la aproximación de las legislaciones de los Estados miembros en materia de marcas, del 22 de octubre de 2008. Diario 0 ficial de la U nión Europea, 8 de noviembre de 2008.

Reglamento (CE) $N^{\circ}$ 40/94 del Consejo de 20 de diciembre de 1993 sobre la marca comunitaria. Diario 0 ficial CE $n^{\circ} \mathrm{L} 11$ de 14 de enero del994.

Reglamento (CE) No 207/2009 del Consejo del 26 de febrero de 2009 sobre la marca comunitaria. Diario 0 ficial de la U nión Europea, 24 de marzo de 2009.

FRANCIA:

Código de la Propiedad Intelectual (Code de la propriété intellectuelle, Version consolidée au 1 janvier 2011). D isponible en : 〈http://www. legifrance.gouv.fr/affichC ode.do?cidT exte=LEG ITEXT 000006069414 > [fecha de consulta: 30 de enero de 2011].

INTERNACIONAL:

Acuerdo sobre los Aspectos de los D erechos de Propiedad Intelectual relacionados con el Comercio (AD PIC), 15 de abril de 1994.

Convenio de París para la Protección de la Propiedad Industrial, 20 de marzo de 1883.

\section{JURISPRUDENCIA CITADA}

Eternit Colombiana S.A. con La Nación Colombiana a través, de la División de Signos Distintivos de la Superintendencia de Industria y Comercio de Colombia (2007): Tribunal de Justicia de la Comunidad Andina, 4 de julio de 2007 (solicitud de interpretación prejudicial). Disponible en: <http://intranet.comunidadandina.org/ D ocumentos/Procesos/53-IP-2007.dochttp://www.google. cl/url?sa=t\& source=we $\mathrm{b} \& \mathrm{~cd}=1 \&$ ved $=0 \mathrm{C}$ BY Q F JAA $\&$ url =http $\% 3 \mathrm{~A} \% 2 \mathrm{~F} \% 2 \mathrm{Fintranet}$. comunidadandina. org\% 2FD ocumentos\% 2FProcesos\% 2F 53-IP-2007.doc\& rct=j\& q=Proceso\% 20053-IP$2007 \&$ ei $=$ ch3ITOS_FcennQ eH OdirAQ \& usg=AF Q jC N F6K cdG 7gZH TeEtaQ Y 7ehQ _s--SuQ \& cad=rja> [Fecha de consulta: 2 de febrero de 2011] 
